\title{
Aumento da participação feminina em competições de programação tecnológicas através da criação de grupos de treinamento e pesquisa
}

\author{
Marcela Sávia Picanço Pessoa ${ }^{1,2}$, Sérgio Cleger Tamayo², Juliany Rodrigues \\ Raiol $^{1,3}$ \\ ${ }^{1}$ Escola Superior de Tecnologia - Universidade do Estado do Amazonas (EST/UEA) \\ Manaus - AM - Brasil \\ ${ }^{2}$ Faculdade Fucapi \\ Manaus - AM - Brasil \\ ${ }^{3}$ Samsung Ocean \\ Manaus - AM - Brasil \\ msppessoa@uea.edu.br, sergio.cleger@gmail.com, julianyraiol@gmail.com
}

\begin{abstract}
This paper presents a strategy to increase the interest of students (specially the women) in participate of programming contests, after the creation of a research and training group. This strategy succeded, increasing the number of students and improving their results in regional contests.
\end{abstract}

Resumo. Este artigo apresenta uma estratégia para despertar o interesse de estudantes, especialmente do sexo feminino, para participar de competições de programação, através da criação de um grupo de treinamento e pesquisa. A estratégia se mostrou eficiente aumentando o número de alunos e melhorando o desempenho em competições regionais.

\section{Introdução}

Sabe-se que a mulher foi de grande importância para o desenvolvimento e disseminação da ciência. Ada Lovelace, com a criação do primeiro algoritmo, Grace Hopper, idealizadora do conceito de sub-rotinas e Dana Urely, primeira mulher engenheira a participar de um projeto na NASA, foram algumas das pioneiras a ingressar e exercer influência em um ambiente majoritariamente masculino. Entretanto, mesmo com esta importante participação feminina na ciência, continua pequeno o número de mulheres que ingressa nos cursos. Segundo Oliveira et al. (2014) a partir dos anos 80 houve um decréscimo no número de mulheres concluintes nos cursos de computação. Estes índices se reproduzem em atividades que envolvam competições de programação tecnológicas.

Para Fisher (2016), o desinteresse feminino em competições de programação acontece, entre outros fatores, pois as competições são originalmente pensadas para participação masculina. Apesar disso, várias iniciativas surgem para tentar aumentar a participação feminina nestas competições. Este artigo apresenta uma estratégia para aumentar a participação feminina na Universidade do Estado do Amazonas - UEA, em Manaus, através da criação de grupo de treinamento e pesquisa, conforme descrito neste artigo. 


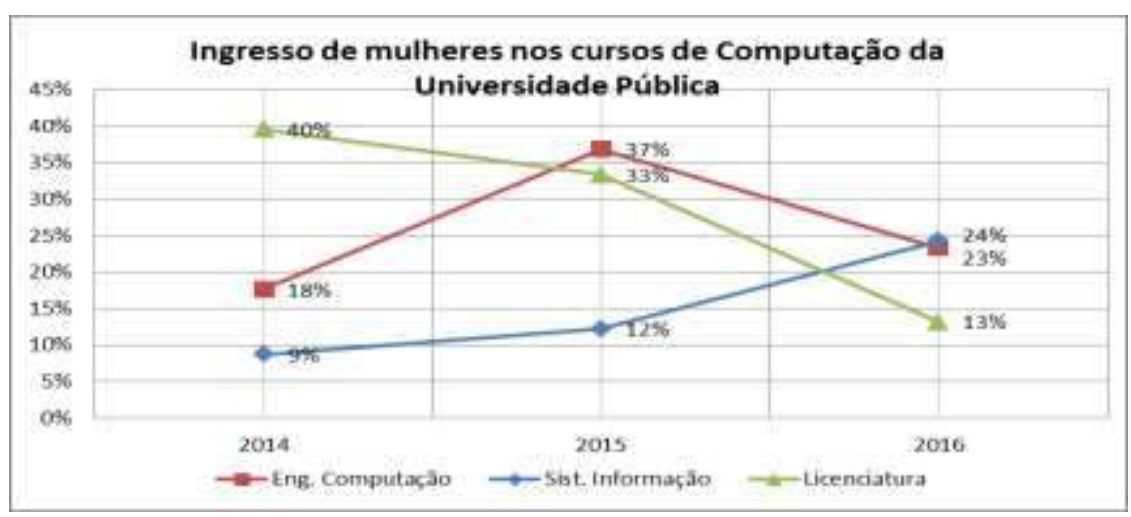

Gráfico 1 - Ingresso de mulheres nos três últimos vestibulares

\section{Cenário de ingresso nos cursos de computação na universidade estadual}

A UEA existe desde 2001, com três cursos na área de computação: Engenharia de Computação, Sistemas de Informação (está no terceiro vestibular e substituiu o curso Tecnólogo em Análise e Desenvolvimento de Sistemas) e Licenciatura em Computação. Porém, o cenário de ingresso de mulheres nestes cursos segue o padrão nacional, sendo em todos eles em menor número que de homens. No Gráfico 1 é possível observar que há um aumento no número de mulheresmulheres que optaram por Sistemas de Informação enquanto que esse percentual diminuiu no curso de Licenciatura em Computação.

Um outro problema que foi observado é que as mulheres desta universidade apresentavam menor interesse em participar de competições de programação tecnológicas, como Maratonas de Programação e Hackatonas. Inclusive entre os meninos não havia a cultura de participar de competições. Até o ano de 2014 a UEA só era representada por uma equipe na etapa regional da Maratona de Programação [MP, 2016], parte do International Contest Programming Contest da Association of Computing Machinery (The ICPC-ACM) [ICPC-ACM 2016] e nunca houve registro de participação feminina oriunda desta universidade na referida competição.

A partir de então, foram tomadas ações para melhorar estes indicadores, através da criação de um grupo de treinamento e pesquisa que utiliza a estratégia descrita a seguir.

\section{Estratégia do grupo}

O grupo é formado por qualquer aluno da universidade que mostre interesse em programação, inclusive de outros cursos como Matemática, Engenharia de Produção e Elétrica, mesmo que mantenha a maioria de seus integrantes oriundos dos cursos de computação. A dinâmica do grupo segue as etapas descritas nesta seção.

\section{Seleção}

Nesta etapa é realizado um conjunto de atividades para incentivar os alunos a participarem do grupo de pesquisa e treinamento. Entre as atividades estão: 1) Visita às salas de aula dos alunos ingressantes na universidade para divulgar o grupo e convidálos a fazer parte; 2) Palestras proferidas por competidores e ex-competidores; 3) 
Encontros para conversas informais com pesquisadores e treinadores de equipes; 4) Divulgação do Movimento Cunhatã Digital (Lauschner et al., 2016) como forma de atrair mulheres; 5) Palestras proferidas por mulheres que atuam na área de computação falando sobre a importância delas para a área.

\section{Treinamento}

Nesta etapa são definidos critérios que desenvolvam as habilidades individuais e em grupo, como: 1) Orientações aos novos integrantes do grupo a respeito de ambientes de competições; 2) Cada novo integrante recebe um aluno veterano que vai ajudá-lo a treinar e tirar as dúvidas mais frequentes; 3) São realizadas orientações e dinâmicas para composição de equipes (desde a chegada de novos membros até a definição das equipes que participarão das competições); 4) Orientação sobre técnicas de trabalho em equipe.

\section{Desenvolvimento}

Nesta etapa são realizadas atividades que busquem melhorar a eficácia de todos os participantes. Cada um identifica suas habilidades e potencialidades individuais e em grupos e o desempenho em ambientes de competição real. Entre as atividades estão: 1) Desenvolvimento de competições internas (simulados) em ambiente de programação real, preferencialmente acontecendo uma vez por semana; 2) Desenvolvimento de competições por tema (segundo cronograma especificado); 3) Participação em competições oficiais (seguindo o cronograma de eventos da região); 4) Encontro semanal para debate e troca de soluções.

\section{Avaliação}

Nesta etapa são realizadas as avaliações dos resultados alcançados, das soluções das equipes, dos aspectos que precisam ser melhorados e a definição de novos objetivos. Esta avaliação acontece após cada competição e tem as seguintes atividades: 1) Debate e discussão de soluções; 3) Avaliação do treinamento e identificação das necessidades das equipes; 4) Definição dos objetivos individuais e em grupos.

\section{Resultados Alcançados}

Em 2015, $1^{\text {a }}$ edição da etapa regional da Maratona de Programação [MP, 2016] após a criação do grupo, a UEA participou com 6 equipes, sendo que em uma delas havia 2 mulheres. Estas equipes participaram também das competições locais que aconteceram.

Para o ano de 2016, o grupo tinha como meta dobrar quantidade de meninas competindo. Foram realizadas reuniões com calouros, os professores do departamento fizeram um trabalho motivacional e com isto, o número de mulheres participante da etapa regional aumentou para 6 , triplicando, desta forma, a participação feminina, além de que, o número de equipes participantes aumentou para 7. Além das competições de programação que aconteceram na cidade, uma equipe participou da VIII Competição Iberoamericana Interuniversitária de Matemática.

Para tentar conhecer a percepção dos integrantes do grupo, foi realizada pesquisa e perguntado a que eles atribuem o aumento da participação feminina nas competições de programação tecnológicas, $90 \%$ dos participantes responderam que atribuem à criação do grupo, conforme apresenta o Gráfico 2. 


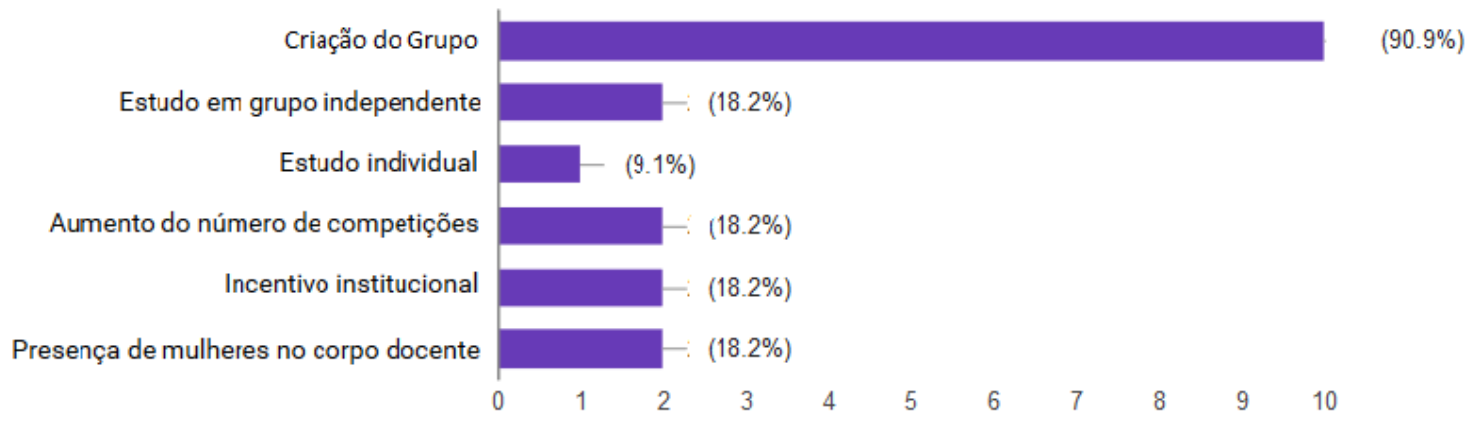

Gráfico 2 - Opinião dos participantes do grupo a respeito das razões que levaram a crescer o número de mulheres em competições de programação.

Para garantir a integração entre os participantes, o grupo se reúne nos laboratórios da UEA. O ingresso de novos alunos é contínuo. A estratégia de estudo é por nível, iniciantes recebem ajuda dos veteranos. A cada semana é passado um conteúdo e aos sábados é feita uma competição com questões relacionadas aos conteúdos da semana.

Como são poucas as alunas que ingressam nos cursos, estas são identificadas e convidadas a participar do grupo. Muito desta ação foi impulsionada pelo trabalho de [Freitas et al., 2016] [Lauschner et al., 2016]. O grande problema é que na UEA os alunos dos cursos de engenharia entram no ciclo básico, embora muitas alunas participem do grupo, algumas optam por outras engenharias e com o tempo preferem ingressar em grupos específicos de seus cursos não dando continuidade ao trabalho.

Em relação às equipes que persistem, um problema que se encontra é que as equipes não tem evoluído em desempenho, porém, observa-se que as mulheres são mais abertas a sugestões de melhoria para novas estratégias. Observa-se ainda que as mulheres têm um posicionamento mais estratégico e de liderança dentro do grupo.

\section{Conclusão}

Este artigo apresentou uma estratégia para aumentar o número de participantes em competições tecnológicas, dando ênfase à participação feminina, através da criação de um grupo de estudo e pesquisa. A criação do grupo foi eficiente em vários aspectos, desde a melhoria na qualidade dos alunos em sala de aula até no desempenho em competições. O grupo teve equipes em todas as competições realizadas na cidade e em $50 \%$ delas conquistou o primeiro lugar. Em relação à participação feminina, houve um grande avanço e cada vez mais se percebe o interesse em participar do grupo e, por consequência, das competições. Algumas ações estão sendo previstas, entre elas a criação de um subgrupo somente com as mulheres.

\section{Agradecimentos}

Agradecemos à diretoria regional da Maratona de Programação (The ACM ICPC), em especial à professora Rosiane de Freitas Rodrigues, pesquisadora da Universidade Federal do Amazonas e uma das principais impulsoras na região amazônica de projeto que incentivam a participação em competições tecnológicas, especialmente a participação feminina. Aos participantes do Projeto Cunhatã Digital agradecemos o 
apoio em todas as atividades e por oportunizar que outras instituições componham a equipe de trabalho.

Parte dos resultados apresentados nesta publicação foi obtida por meio de atividades de Pesquisa e Desenvolvimento do projeto SAMSUNG OCEAN, patrocinado pela Samsung Eletrônica da Amazônia Ltda., apoiado pela SUFRAMA sob os termos da Lei Federal N 8.248/91.

\section{Referências}

Fisher, M., and Cox, A. (2006) "Gender and Programming Contests: Mitigating Exclusionary Practices" In Informatics in Education 5 (1): p47-62.

Freitas, R., Gomes, L., Conte, T. (2016) "Projeto SciTechGirls: desenvolvimento de aplicativos e participação em competições de programação científicas e tecnológicas" In: XXXVI Congresso da Sociedade Brasileira de Computação 2016, Porto Alegre. Anais CSBC 2016, p 1465-1474.

Lauschner, Tanara (2016). Cunhantã Digital: programa de incentivo à participação demulheres da região amazônica na Computação e áreas afins. XXXVI Congresso da Sociedade Brasileira de Computação.

Manzoor, S. (2006) "Analyzing programming contest statistics", In Perspectives on computer science competitions for (high school) students. http://www.bwinf.de/competition-workshop/RevisedPapers/13_Manzoor_revbetter.pdf.

MP (2016). Maratona de programação. The ICPC-ACM South America - Brazil. Sociedade Brasileira de Computação. Disponível em http://maratona.ime.usp.br/.

Oliveira, A.C., Moro, M.M., Prates, R.O. (2014) "Perfil Feminino em Computação: Análise Inicial” In: XXII Workshop sobre Educação em Computação, Brasília, DF, p. 14651474. 